\title{
Cancer-associated thrombosis, low-molecular- weight heparin, and the patient experience: a qualitative study
}

This article was published in the following Dove Press journal:

Patient Preference and Adherence

8 April 2014

Number of times this article has been viewed

\author{
Siwan Seaman' \\ Annmarie Nelson ${ }^{2}$ \\ Simon Noble ${ }^{2}$ \\ 'Department of Palliative Medicine, \\ Royal Gwent Hospital, Newport, \\ Wales, UK; ${ }^{2}$ Marie Curie Palliative \\ Care Research Unit, Cardiff \\ University, Cardiff, Wales, UK
}

Correspondence: Simon Noble Marie Curie Palliative Medicine Research Group, Sixth Floor, Neuadd Meirionnydd, Cardiff University, Heath Park Campus, CFI 4 4YS, Wales, UK

Tel +442920687500

Fax +44292068 7501

Email simon.noble@wales.nhs.uk
Background: Venous thromboembolism is a common complication of cancer and its treatments. Treatment of cancer-associated thrombosis (CAT) differs from treatment of thrombosis in noncancer patients, requiring a daily injection of low-molecular-weight heparin (LMWH) for 6 months instead of an oral anticoagulant. Previous research suggested LMWH is an acceptable intervention in the treatment of CAT, yet clinical practice and therapeutic opportunities have changed in the decade since the study was conducted. Furthermore, in the previous study there was acknowledged selection bias in participant recruitment. There is increasing clinical use of the novel oral anticoagulants, although their efficacy and safety is yet to be demonstrated within the cancer population. The experience of patients receiving anticoagulation for CAT will inform future practice with respect to quality of life and adherence to anticoagulation therapy.

Aim: To explore the acceptability of long-term LMWH for the treatment of CAT in the contexts of living with cancer and quality of life.

Design: Qualitative study of cancer patients who had been receiving LMWH for at least 3 months for CAT was undertaken. Audiotaped semistructured interviews were conducted and transcribed. Thematic analysis was undertaken until theoretical saturation.

Setting/participants: Fourteen patients attending a palliative care or CAT clinic were interviewed. Participants had been receiving LMWH for a median 6 months.

Results: Participants reported distressing symptoms associated with symptomatic CAT, which they rated as worse than their cancer experiences. LMWH was considered an acceptable intervention despite challenges of long-term injections. Several adaptive techniques were reported to optimize ongoing injections. Participants would only favor a novel oral anticoagulant if it was equivalent to LMWH in efficacy and safety.

Conclusion: Although LMWH remains an acceptable intervention for the treatment of CAT, its long-term use is associated with bruising and deterioration of injection sites. These are considered an acceptable trade-off against their strongly negative experiences of symptomatic venous thromboembolism.

Keywords: venous thromboembolism, qualitative, experience, cancer, NOAC, acceptability, quality of life

\section{Introduction}

Venous thromboembolism (VTE), comprising deep vein thrombosis (DVT) and pulmonary embolism $(\mathrm{PE})$, is a highly prevalent complication of cancer and its treatments. ${ }^{1,2}$ In addition to causing acute and long-term morbidity, it remains the number one cause of death during chemotherapy and is the most common cause of all cancer deaths, second only to disease progression. ${ }^{3,4}$ Risk factors for VTE in malignant disease have 
been extensively reported; increasing age, metastatic burden, and chemotherapy further add to the prothrombotic state brought about by the release of tumor procoagulants such as tissue factor. ${ }^{1}$

The challenges of managing cancer-associated thrombosis (CAT) are well recognized; cancer patients are at greater risk of recurrent VTE than those without malignancy, and rates are greatest in advanced-stage disease. ${ }^{4-6}$ Furthermore, anticoagulation therapy is associated with higher bleeding complications in cancer patients than in noncancer patients, and this increases with metastatic progression..$^{5,7,8}$

Clinical guidelines recommend that the first-line treatment of CAT requires 3-6 months anticoagulation with weight-adjusted low-molecular-weight heparin (LMWH). ${ }^{9-11}$ The evidence supporting this is compelling, with metaanalysis from four randomized controlled trials identifying a $50 \%$ relative risk reduction in recurrent VTE without increased bleeding rates. ${ }^{12-15}$ Because $47 \%-65 \%$ of those enrolled had metastatic disease, these recommendations are also considered appropriate in the advanced-cancer setting. ${ }^{16-18}$ In addition to greater efficacy, other potential benefits to LMWH include minimal need for monitoring, fewer drug-drug interactions, and consistent absorption of the drug owing to its parenteral route. ${ }^{19}$ The guidelines also recommend that in patients with active cancer who thus have an ongoing risk for recurrent CAT, consideration should be given to indefinite anticoagulation. ${ }^{9-11}$

In 2005, Noble and Finlay published a qualitative study exploring the acceptability of LMWH in 40 cancer patients receiving long-term $\mathrm{LMWH}$ for $\mathrm{CAT}^{20}$ Major themes reported included acceptability of the injection, simplicity of dosing, freedom, and a sense of optimism. This was the first paper to suggest that LMWH was an acceptable intervention, and it has been cited in major international clinical guidelines. ${ }^{10,11,21,22}$ However, it is now appropriate to reevaluate the study and acknowledge several limitations that have become more apparent, ten years on.

First, one needs to consider the study in the context of standard practice at the time. In 2004, when the interviews were undertaken, patients with CAT were treated first-line with warfarin because the translation of new evidence into practice had not yet been realized. As a result, the majority of patients receiving LMWH had been converted from warfarin after complications such as bleeding, recurrent thrombosis and drug-drug interactions. This introduced a selection bias, in particular since the acceptability of LMWH may reflect the bad experience on warfarin rather than a favorable LMWH experience per se.
Second, interviewed patients had been receiving $\mathrm{LMWH}$ for a mean of 42 days. Although this may be sufficient time to gauge the patient experience of the drug in the early part of the VTE treatment schedule, the standard length of treatment with LMWH is 6 months. How someone will feel after self-injecting for 6 months may differ considerably from his or her experiences over a single month.

Finally, it is important to consider the impact that the newly evaluated novel oral anticoagulants (NOACs) may have on VTE treatment. Dabigatran, a direct thrombin inhibitor, and the factor Xa inhibitors rivaroxaban and apixaban have all been evaluated for the treatment of DVT and PE and have demonstrated noninferiority to warfarin. ${ }^{23-26}$ Although these treatments obviate the need for injections, there is no readily available method to monitor activity of these drugs or to reverse them in the event of bleeding. Furthermore, cancer patients made up less than $7 \%$ of the sample in any of the studies, and without confirmation of noninferiority over LMWH, it would be premature to recommend NOACs as first-line treatment of CAT. Nevertheless, it is possible that patients may prefer an oral agent to a long-term injection even if it has lower efficacy. In a field where quality of life is of utmost importance, it is important to seek patients' views on this.

We therefore sought to explore the acceptability of long-term LMWH for the treatment of VTE in patients with advanced cancer.

\section{Methods Data collection}

Patients attending a dedicated CAT clinic, within a regional cancer center, were sequentially screened for inclusion into the study, through the review of clinical notes and, where appropriate, drug charts. The last author (SN) undertook screening. All eligible patients were invited to participate. Inclusion criteria were: 1) receiving LMWH for a proven new VTE (DVT or PE) and having received such treatment for at least 3 consecutive months; 2) diagnosis of active advanced cancer, to include locally advanced cancers with no curative treatment available (eg, primary brain tumors and cancers with distant metastatic spread); and 3) ability to consent and participate in a 30-minute interview. Exclusion criteria included: 1) receiving oncological treatment with intention to cure; and 2) presence of a central venous catheter.

All participants provided written consent. Semistructured interviews were carried out over a 6-month period from February-July 2013 by the first author, as part of a supervised master's degree research project. The researcher was an 
experienced palliative care physician, trained in conducting qualitative research. Following initial pilot testing, the interviews were conducted in the patient's home and guided by a prompt list to ensure that the same issues were discussed at each interview. The researcher had no prior relationship with participants or declared clinical interest in CAT management. Data were elicited on the following: 1) what patients understood about their condition; 2) what they understood about their treatment; 3 ) the practicalities of their LMWH treatment; 4) positive aspects of being on LMWH; and 5) negative aspects of being on LMWH.

To facilitate this, questions were open-ended, with the use of prompts to probe further into issues that arose as significant or meaningful to the participant. Interviews were digitally recorded and transcribed verbatim. Field notes were also taken. Interviews took approximately 30 minutes each. No repeat interviews were necessary, and no aspect of any of the transcripts required additional checking with participants.

Ethical approval had been obtained through the National Health Service of South Wales Research Ethics Committee. As part of the ethical review, it was recommended that specific questions be introduced to explore patient attitudes to alternative anticoagulants such as the NOACs and whether they would prefer these to the LMWH. Accordingly, the following three questions were added to the interview schedule:

1. If, in the future, there were a tablet available that was worked as well as the injections for cancer-associated blood clots, which would you choose?

2. What if there were a new tablet that had been tested to confirm that it worked for clots in noncancer patients but had not been tested specifically to see how effective it was in patients with cancer who had clots?

3. What if there were a tablet that worked as well as the injection, but we had no way of monitoring whether your blood was too thin or too thick on it?

\section{Analysis}

The data were analyzed using thematic content analysis. Initial coding was undertaken independently by SS and then validated by SN. This involved the following stages:

1. The first two transcripts were read line by line and annotated with initial comments.

2. The pair of transcripts was compared to identify relevant concepts and commonalities.

3. These were coded and initial comments were grouped into themes.
4. Further interviews were conducted and further themes were identified.

5. Connections between themes were developed until an organized master list and thematic rationale were achieved.

6. New themes were tested against the previous transcripts, as nonrecurring themes were tested against following transcripts.

7. Interviews were carried out until theoretical saturation was achieved; that is, no new themes were identified and nothing new was added to what had already been elicited during the ongoing analysis.

Theoretical saturation was achieved at eight interviews. However, in order to optimize the breadth of primary cancer diagnoses and ages of participants, it was agreed that a further six participants should be interviewed. This was done to increase the reliability of findings.

\section{Results}

\section{Participant characteristics}

Screening of 40 sequential CAT outpatients identified 14 suitable patients. Twenty of those screened were ineligible due to being on LMWH for less than 3 months; the remainder of excluded patients had localized cancer only. All 14 patients who were approached agreed to participate in the study. Patient characteristics are summarized in Table 1. Patients were 52-84 years of age (median 66 years). Patients had been receiving LMWH for treatment of confirmed VTE (PE $n=8$, DVT $n=6$ ) for 14-148 weeks (median 26 weeks). All patients had commenced LMWH at diagnosis of CAT, with the exception of one (patient 8) who had received warfarin for 3 months and was then diagnosed with cancer and changed to LMWH.

Major themes and their associated subthemes are illustrated in Figure 1. Major themes identified were impact of VTE, acceptability of LMWH, and views on the novel oral anticoagulants. These are discussed below with accompanying interview excerpts. Excerpts of interview were selected on the basis of two criteria. First, they illustrate the issue being discussed, and second, an attempt was made to use a spread of participants rather than rely on a few individuals.

\section{Major theme I: impact of VTE}

All patients considered that being diagnosed with a VTE had a major impact on their life, seeing it as a distinct entity rather than an integral part of their cancer illness. They 
Table I Characteristics of study participants including age, sex, performance status, cancer primary and evidence of distant of local spread, cancer stage

\begin{tabular}{|c|c|c|c|c|c|c|c|c|}
\hline $\mathbf{P t}$ & Age & Sex & PS & $\begin{array}{l}\text { Primary cancer; } \\
\text { metastases }\end{array}$ & Current stage & PE or DVT & $\begin{array}{l}\text { Injection given by } \\
\text { self, caregiver, or } \\
\text { district nurse }\end{array}$ & $\begin{array}{l}\text { LMWH } \\
\text { treatment } \\
\text { duration }\end{array}$ \\
\hline 1 & 57 & $M$ & 1 & $\begin{array}{l}\text { Renal cell; lung and soft } \\
\text { tissue metastases }\end{array}$ & IV & PE & Self & 18 months \\
\hline 2 & 84 & M & 2 & Stomach & $\begin{array}{l}\text { Locally advanced with } \\
\text { lymph node involvement }\end{array}$ & PE & Self & 4 months \\
\hline 3 & 53 & $\mathrm{~F}$ & 2 & Breast; bone metastases & IV & DVT & Self & 29 months \\
\hline 4 & 61 & $\mathrm{~F}$ & I & Ovarian & Illc & $\begin{array}{l}\text { Axillary vein } \\
\text { thrombosis }\end{array}$ & Caregiver & 4 months \\
\hline 5 & 83 & $\mathrm{~F}$ & 2 & Ovarian & IV & DVT & Self & 3 months, 2 weeks \\
\hline 6 & 77 & $\mathrm{~F}$ & 4 & Colorectal & Unknown & PE & District nurse & 18 months \\
\hline 7 & 83 & $\mathrm{~F}$ & I & Bowel; liver metastases & IV & PE & Self & 3 months, 3 weeks \\
\hline 8 & 71 & $M$ & 2 & Cholangiocarcinoma & IV & DVT & Self & 6 months \\
\hline 9 & 64 & $M$ & I & Lung; cervical nodes & IV & DVT & Self & 6 months \\
\hline 10 & 57 & M & 2 & $\begin{array}{l}\text { Colon cancer; liver } \\
\text { metastases }\end{array}$ & IV & PE & Caregiver & 7 months \\
\hline II & 52 & $\mathrm{~F}$ & 2 & Ovarian cancer & Illc & $\mathrm{PE}$ & Self & 6 months \\
\hline 12 & 65 & $\mathrm{~F}$ & I & $\begin{array}{l}\text { Breast; lymph nodes and } \\
\text { bone metastases }\end{array}$ & IV & PE & Self & 8 months \\
\hline 13 & 66 & $\mathrm{~F}$ & I & $\begin{array}{l}\text { Breast; lymph nodes, lung, } \\
\text { and bone metastases }\end{array}$ & IV & DVT & Self & 34 months \\
\hline 14 & 72 & $M$ & 2 & Colorectal; mesenteric nodes & IV & $\mathrm{PE}$ & Self & 6 months \\
\hline
\end{tabular}

Abbreviations: DVT, deep vein thrombosis; F, female; LMWH, low-molecular-weight heparin; M, male; PE, pulmonary embolus; PS, performance status; Pt, patient.

identified three key areas that VTE had affected their lives, namely through the symptom burden of VTE, its impact in the context of their cancer journey, and its impact on their activities of daily living.

\section{Subtheme: symptom burden of VTE}

Participants described the symptoms of VTE as a distressing experience. The majority of participants gave vivid descriptions of their symptoms, further emphasizing the impact of the symptoms.

My leg had started aching and it was swelling up and I thought 'this isn't right' [...] It was burning and when you touched it was sort of sinking into it, you know, leaving finger marks. [PT3]

All of the sudden it was like something hit me right there (makes a fist and hits center of chest over sternum). I just went back and I'm like this (breathes heavily as if gasping for breath) breathing in through the nose out through the mouth I was doing. Anyway, it passed off but it scared me I can tell you, it was like something I haven't had, so the following day I had trouble with ... I was out of breath and the rest of it. [PT5]

I couldn't breathe, I literally couldn't breathe and couldn't talk. [PT6]
I had a terrible pain in my chest which I thought was indigestion [...] and I'd started coughing up a little bit of blood. [PT13]

\section{Subtheme:VTE in the context of cancer}

For many participants, the diagnosis of a PE came as a greater shock than being diagnosed with cancer.

I never broke down when I was told about the cancer [...] I had the operation, went on the chemo, everything. The only time I broke down was when I went back in hospital when they told me I had blood clots [...] the cancer to a point they can treat, hold it back - blood clots they go so quick and that frightened me, it was the only time I broke down. [PT13]

The knowledge that VTE is a potentially fatal condition, coupled with distressing symptoms at presentation, reinforced the distress experienced. For many, their doctor highlighted the seriousness of the condition, although some already had knowledge of the danger of VTE.

What he said to me, "It's the clot on your lung that's going to kill you, not the cancer the way it's going" - that's the way he put it to me like. [PT8]

It frightened the life out of me, I was more scared of that than the cancer. You know blood clots can kill you like 


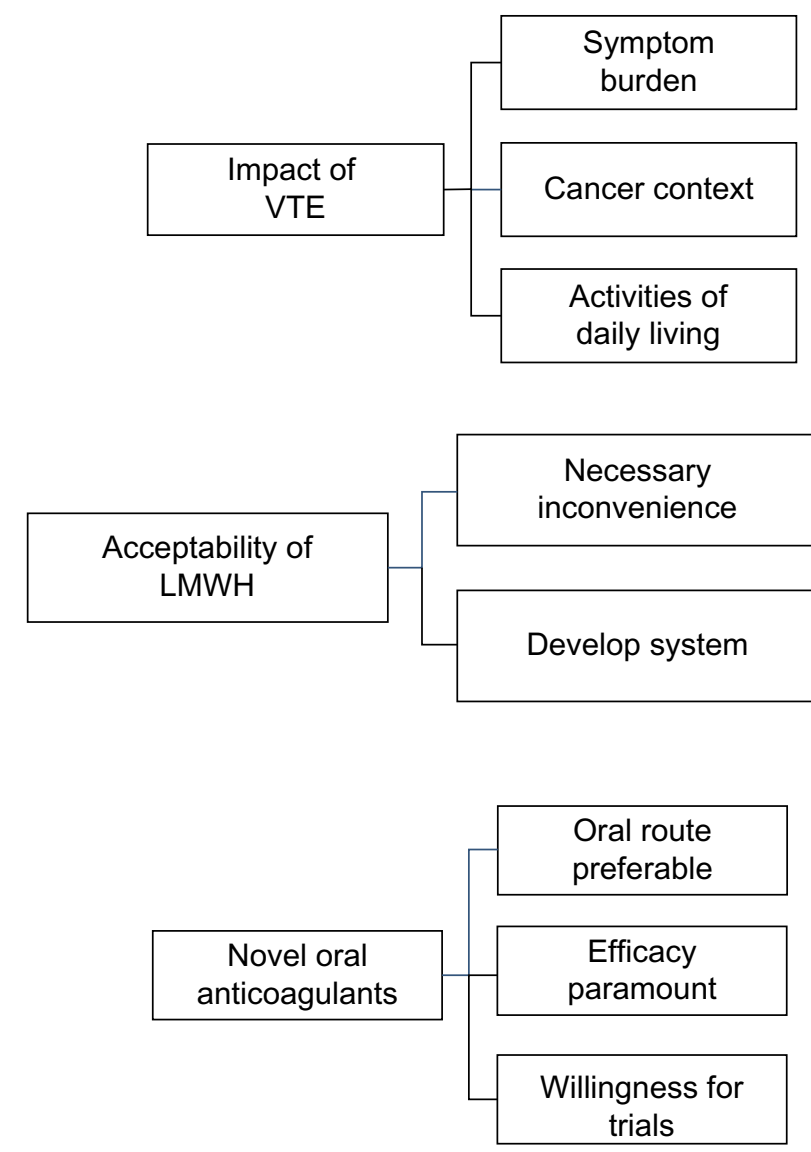

Figure I Major themes and associated subthemes.

Abbreviations: LMWH, low-molecular-weight heparin; VTE, venous thromboembolism.

that (clicks fingers), cancer you've got a little bit of chance, you know. [PT13]

I was having a pain in my leg and so I went to my doctor and I said, "Doc, look, they're going to cure me of cancer but I'm going to die of a clot." [PT2]

For some participants, the cancer journey had been relatively symptom free and thus the experiences of VTE overshadowed the negative experienced attributed to cancer.

I've had more trouble with the chest part of me than I have with the bottom part of me (colorectal cancer). [PT6]

\section{Subtheme: impact on activities of daily living}

The physical impact on activities of daily living was profound. Participants reported that symptoms attributable to VTE prevented or reduced basic activities such as going to the toilet or talking on the telephone.

I couldn't do anything, I couldn't talk on the telephone or anything - it was that bad. [PT12]
You get up to go to the toilet and you're all huffing and puffing when you get back. [PT11]

Patients who were previously independent reported being unable to do daily activities around the house or to mobilize unaided.

Oh, I was very breathless. Oh my goodness, even bending down to the washing machine to put a wash in I was gasping for air. [PT11]

I was getting awful shortage of breath. I think the clot moved from the leg to my lung. I was having terrible shortage, I couldn't walk, I was going to hospital in a wheelchair - that's how bad it was, I never done that in my life. [PT8]

\section{Major theme 2: acceptability of LMWH}

All participants found LMWH to be an acceptable intervention for the treatment of CAT despite reporting a variety of symptoms associated with injecting.

Sometimes when the needle goes in you don't even feel the injection; other times the needle, it's as if the needle's blunt and it won't go through the skin ... you know, you do it and then you bleed. Other than that there's no discomfort at all. [PT9]

I've got used to it like we all do everything in life, but it's ... whilst it's only a small injection, it's quite painful. [PT10]

It's not a problem to inject myself; I'll do that for as long as I have to. [PT9]

\section{Subtheme: necessary inconvenience}

Participants considered the downside of a daily injection to be an acceptable, necessary tradeoff to keep them free of thrombotic recurrence. This is likely to reflect their knowledge of the potentially fatal complications of VTE, coupled with the experience of distressing symptoms at presentation.

I'll stick the needles in until doomsday - it doesn't make any odds to me as long as they're keeping me going. [PT2]

Well I've got to, haven't I? It's either that or I peg out, like. So you see that it's doing you good. I've got to do it, simple as that, no argument. [PT8]

Well, if it keeps me alive it's as simple as that. I'd take poison to stay alive. It's not nice, you're tired every morning, pants down and injection but there you go - that's life, isn't it, and as I say, it's keeping me alive, so that's the important bit. [PT9] 


\section{Subtheme: systematic approach to injections}

Participants described the development of strict routines and rituals to ensure LMWH was administered on time and without fail. Only one participant reported ever missing a dose.

I've got my routine. I'm usually in bed by 10 o'clock. So, I've got them all upstairs, so I take my tablet, get my injection, do it, put it in the thing, then my husband fetches them down and puts them in the burn bin. [PT2]

I usually take them between 8 and half past 8 . And then I know it's done, and I don't forget for the day, then, because someone I was talking to, he was saying "You don't do it in the night, do you?" and I said, "No, I get up, have my cup of tea then 8 , half past 8 do it." [PT13]

[My husband's] got his phone on alarm and when the alarm goes off he gives me the injection. [PT4]

The majority of participants had received more than 180 injections at the time of interview. All reported long-term consequences of injections to include bruising and the development of subcutaneous fibrous tissue under some injection sites. Consequently, they developed systems to continue injecting in a way that would allow bruised areas to recover. They reflected a confidence to be pragmatic in finding ways to continue with their injections.

This side is the odd dates and this side is the even dates. So the even date had its share today, other than that you're ... well, not everyone's like me but I'd be, "Now what date was it yesterday when I done it?" And it's a routine now, you see. It's better. You know. I keep between 8 and quarter past, so I have my ablution, then I give my injection, then I get dressed. [PT5]

I'm using the tops of my legs now so it isn't as painful. I was using my stomach but after a while your stomach gets really hard and then you've got to really force them in. $[\mathrm{PT} 8]$

I've had close to 200 injections now, so after a while you get a few little lumpy bits ... you know, obviously you move away from those areas a little bit, I suppose, and sometimes the needle doesn't quite go in - you've got to shove it in a bit. [PT10]

\section{Major theme 3: views on NOACs Oral route preferable}

When given a hypothetical scenario in which patients could have the option of a tablet or injection of equal efficacy to treat their CAT, the majority of patients would choose to have a tablet.
It would have to be the tablet. Most definitely. [PT10]

However, not all patients were adamant in their preference for a tablet; one patient considered the injection to reduce the burden of tablets and another had grown accustomed to injections and was indifferent to change.

I don't mind either, I suppose. I'm not fussed on tablets, I take so many a day. [PT4]

Well I don't know. It would be probably ... well, I can't

say ... I've got used to injecting, but who's to say? [PT5]

\section{Efficacy paramount}

Participants favored efficacy over convenience, expressing a preference for injections over a theoretical tradeoff of reduced efficacy with oral medication. The distressing symptoms associated with VTE are likely to have influenced their satisfaction with LMWHs.

Having been through what I know now, I suppose if I was asked that question at the start, "Look, tablet form but it's not clinically trialled or whatever, we haven't got any data on it or an injection which we believe at this moment in time is more effect[ive]," I probably would have gone for the injection. [PT10]

I'd opt for the injection ... as I said, I don't mind trying new things, but with reservations. I've gone through this now for nearly 11, so I think I know a little bit more than somebody who's just had it and I would have to be reassured. [PT13]

The ability to monitor anticoagulation was also considered an important factor for some patients. This was of particular relevance to those with experience monitoring their current anticoagulation therapy.

They phoned up [...] and they said can you come up straight away because your factor Xa is way too high, and they reduced my dose. [PT1]

If there's no way of monitoring the effect it's having on your blood, then you don't know what it's doing. [PT1]

\section{Willing to engage in clinical trials}

Some participants spontaneously expressed a willingness to participate in clinical trials involving new anticoagulants. Reasons for this were in part altruistic and part opportunity to access therapies later in their disease journey.

Well, I don't know ... as I said, I'm going to pop off anyway so somebody's got to try these things out - so I'd be quite happy, I think, to give it a go. [PT6] 
There will be a time down the line, maybe, when I'll try something experimental. I really don't know and we haven't got that far yet and I'm not asking those questions ... if there are any things some way down the line that are options, I am happy to consider those. [PT10]

\section{Discussion}

VTE is a common condition facing cancer patients and its treatment requires 6 months of anticoagulation with a daily LMWH injection. Previous research in patients with advanced cancer who received LMWH for a mean 42 days found the intervention to be acceptable in the context of previous poor experiences with warfarin. ${ }^{20}$

The findings of the current study suggest that LMWH is still an acceptable intervention in this population and that most patients are willing to continue with the treatment beyond 6 months. This is not to say that the treatment is without downsides: the injection itself is painful, albeit short-lived, and bruising is common. Long-term use is associated with the development of subcutaneous lumps and further bruising, making it harder to find suitable places for injecting.

Although confirmation of the acceptability of LMWH is not a new finding per se, this study offers additional insights into patient experiences and attitudes. In previous research, LMWH was considered acceptable in the context of previous poor experiences with warfarin. In this study, all but one patient had started on LMWH with no other drug as comparator. This study suggests that patients experiencing distressing symptoms from VTE considered LMWH a "necessary evil" in treating a potentially life-threatening condition. In addition, it suggests that some patients will comply with indefinite anticoagulation therapy if required.

Most participants reported the symptoms associated with VTE to be profound, with both physical and psychological distress described. It is likely that their acceptance of longterm LMWH reflected their negative experiences of VTE coupled with the ongoing risk of VTE recurrence. This is not dissimilar to patients' attitudes about chemotherapy side effects, where patients will accept a degree of symptom tradeoff in order to be treated for their cancer. ${ }^{27-29}$ Our results suggest that patients with advanced cancer are willing to undergo long-term LMWH injections for the treatment of VTE and do not see it compromising their quality of life when weighed up against the risk of VTE.

This study also raises insights into the potential role of the NOACs, which warrant further systematic investigation. Although most patients would prefer the oral route to the subcutaneous route, this would only be on the proviso of equal efficacy and safety. Because none of the NOACs have demonstrated noninferiority against LMWH, it would seem counterintuitive to recommend NOACs routinely as first-line treatment of CAT. There are limitations to these data; the questions regarding NOACs were not part of the original protocol but were included following strong recommendation at ethical review. The questions did not allow for patients to express what degree of tradeoff between efficacy and convenience would be acceptable to them; for example, it is possible that a patient might be willing to take a tablet that was $80 \%$ as effective as the injection. This warrants further attention before drawing strong conclusions, and a discretechoice methodology study is planned to further this.

It is important to acknowledge the limitations of this study when considering its clinical implications. First, this study was undertaken within a single institution through a dedicated CAT clinic. It is possible that results generated through a specialist setting may not represent those from a more generalist environment. Furthermore, it is possible that managing CAT within a specialist environment affords the patient greater access to information and understanding of the rationale for using LMWH. Increased understanding may consequently improve compliance and tolerance of the intervention. Second, although there was strong consistency between participant responses, with no further themes emerging beyond the sixth interview, the sample size was too small to draw conclusions worthy of changing practice.

In conclusion, this study adds further information to what is already known about VTE in the palliative care setting. First, it suggests that CAT produces a significant symptomatic and psychological burden. One could thus argue that, considering that this condition is known to be common in advanced cancer, a greater emphasis should be given to research and education within the specialty. Second, it confirms that, despite several clear downsides to long-term LMWH therapy, patients are willing to persevere with the treatment and will even work to overcome barriers in order to continue with the injections. Finally, the study highlights the need to further explore the role of NOACs, not only for the treatment of VTE in palliative care, but for cancer patients as a whole.

\section{Acknowledgment}

This study was funded by a research bursary awarded by the Thrombosis Research in Advanced Disease (TRAD) Alliance. 


\section{Disclosure}

SN: all honoraria donated to charity for lectures (LEO Pharma Inc., Pfizer Inc., Boeringer Ingelheim $\mathrm{GmbH}$ ) and consultancy (LEO Pharma Inc., Pfizer Inc.). Grant support for investigator initiated research (LEO Pharma Inc.). The other authors report no other conflicts of interest in this work.

\section{References}

1. Noble S, Pasi J. Epidemiology and pathophysiology of cancer-associated thrombosis. Br J Cancer. 2010;102 Suppl 1:S2-S9.

2. White RH. The epidemiology of venous thromboembolism. Circulation. 2003;107(23 Suppl 1):I-4-I-8.

3. Khorana AA, Francis CW, Culakova E, Kuderer NM, Lyman GH. Thromboembolism is a leading cause of death in cancer patients receiving outpatient chemotherapy. J Thromb Haemost. 2007;5(3):632-634.

4. Blom JW, Doggen CJ, Osanto S, Rosendaal FR. Malignancies, prothrombotic mutations, and the risk of venous thrombosis. JAMA. 2005;293(6):715-722.

5. Prandoni P, Lensing AW, Piccioli A, et al. Recurrent venous thromboembolism and bleeding complications during anticoagulant treatment in patients with cancer and venous thrombosis. Blood. 2002;100(10): 3484-3488

6. Noble $\mathrm{S}$. The challenges of managing cancer related venous thromboembolism in the palliative care setting. Postgrad Med J. 2007;83:671-674.

7. Hutten BA, Prins MH, Gent M, Ginsberg J, Tijssen JG, Büller HR. Incidence of recurrent thromboembolic and bleeding complications among patients with venous thromboembolism in relation to both malignancy and achieved international normalized ratio: a retrospective analysis. J Clin Oncol. 2000;18(17):3078-3083.

8. Bona RD, Sivjee KY, Hickey AD, Wallace DM, Wajcs SB. The efficacy and safety of oral anticoagulation in patients with cancer. Thromb Haemost. 1995;74(4):1055-1058.

9. Kearon C, Akl EA, Comerota AJ, et al; American College of Chest Physicians. Antithrombotic therapy for VTE disease: Antithrombotic Therapy and Prevention of Thrombosis, 9th ed: American College of Chest Physicians Evidence-Based Clinical Practice Guidelines. Chest. 2012;141(Suppl 2):e419S-494S.

10. Farge D, Debourdeau P, Beckers M, et al. International clinical practice guidelines for the treatment and prophylaxis of venous thromboembolism in patients with cancer. $J$ Thromb Haemost. 2013;11(1):56-70.

11. Lyman GH, Khorana AA, Kuderer NM, et al; American Society of Clinical Oncology Clinical Practice. Venous thromboembolism prophylaxis and treatment in patients with cancer: American Society of Clinical Oncology clinical practice guideline update. J Clin Oncol. 2013;31(17):2189-2204.

12. Lee AY, Levine MN, Baker RI, et al; Randomized Comparison of LowMolecular-Weight Heparin versus Oral Anticoagulant Therapy for the Prevention of Recurrent Venous Thromboembolism in Patients with Cancer (CLOT) Investigators. Low-molecular-weight heparin versus a coumarin for the prevention of recurrent venous thromboembolism in patients with cancer. $N$ Engl J Med. 2003;349(2):146-153.

13. Hull RD, Pineo GF, Brant RF, et al; LITE Trial Investigators. Long-term low-molecular-weight heparin versus usual care in proximal-vein thrombosis patients with cancer. Am J Med. 2006;119(12):1062-1072.

14. Meyer G, Marjanovic Z, Valcke J, et al. Comparison of low-molecularweight heparin and warfarin for the secondary prevention of venous thromboembolism in patients with cancer: a randomized controlled study. Arch Intern Med. 2002;162(15):1729-1735.
15. Deitcher SR, Kessler CM, Merli G, Rigas JR, Lyons RM, Fareed J; ONCENOX Investigators. Secondary prevention of venous thromboembolic events in patients with active cancer: enoxaparin alone versus initial enoxaparin followed by warfarin for a 180-day period. Clin Appl Thromb Hemost. 2006;12(4):389-396.

16. Noble SI, Shelley MD, Coles B, Williams SM, Wilcock A, Johnson MJ; Association for Palliative Medicine for Great Britain and Ireland. Management of venous thromboembolism in patients with advanced cancer: a systematic review and meta-analysis. Lancet Oncol. 2008;9(6): 577-584.

17. Soto-Cárdenas MJ, Pelayo-García G, Rodríguez-Camacho A, SeguraFernández E, Mogollo-Galván A, Giron-Gonzalez JA. Venous thromboembolism in patients with advanced cancer under palliative care: additional risk factors, primary/secondary prophylaxis and complications observed under normal clinical practice. Palliat Med. 2008;22(8):965-968.

18. Noble SI, Hood K, Finlay IG. The use of long-term low-molecular weight heparin for the treatment of venous thromboembolism in palliative care patients with advanced cancer: a case series of sixty two patients. Palliat Med. 2007;21(6):473-476.

19. Akl EA, Barba M, Rohilla S, et al. Low-molecular-weight heparins are superior to vitamin $\mathrm{K}$ antagonists for the long term treatment of venous thromboembolism in patients with cancer: a cochrane systematic review. J Exp Clin Cancer Res. 2008;27:21.

20. Noble SI, Finlay IG. Is long-term low-molecular-weight heparin acceptable to palliative care patients in the treatment of cancer related venous thromboembolism? A qualitative study. Palliat Med. 2005;19(3):197-201.

21. Kearon C, Kahn SR, Agnelli G, Goldhaber S, Raskob GE, Comerota AJ; American College of Chest Physicians. Antithrombotic therapy for venous thromboembolic disease: American College of Chest Physicians Evidence-Based Clinical Practice Guidelines (8th ed). Chest. 2008;133(Suppl 6):454S-545S.

22. MacLean S, Mulla S, Akl EA, et al; American College of Chest Physicians. Patient values and preferences in decision making for antithrombotic therapy: a systematic review: Antithrombotic Therapy and Prevention of Thrombosis, 9th ed: American College of Chest Physicians Evidence-Based Clinical Practice Guidelines. Chest. 2012; 141(Supp1 2):e1S-e23S.

23. Schulman S, Kearon C, Kakkar AK, et al; RE-COVER Study Group. Dabigatran versus warfarin in the treatment of acute venous thromboembolism. N Engl J Med. 2009;361(24):2342-2352.

24. Bauersachs R, Berkowitz SD, Brenner B, et al; EINSTEIN Investigators. Oral rivaroxaban for symptomatic venous thromboembolism. $N$ Engl J Med. 2010;363(26):2499-2510.

25. Büller HR, Prins MH, Lensin AW, et al; EINSTEIN-PE Investigators. Oral rivaroxaban for the treatment of symptomatic pulmonary embolism. N Engl J Med. 2012;366(14):1287-1297.

26. Agnelli G, Buller HR, Cohen A, et al; PLIFY-EXT Investigators. Apixaban for extended treatment of venous thromboembolism. $N$ Engl J Med. 2013;368(8):699-708.

27. Liu G, Franssen E, Fitch MI, Warner E. Patient preferences for oral versus intravenous palliative chemotherapy. J Clin Oncol. 1997;15(1): $110-115$.

28. Borner MM, Schoffski P, de Wit R, et al. Patient preference and pharmacokinetics of oral modulated UFT versus intravenous fluorouracil and leucovorin: a randomised crossover trial in advanced colorectal cancer. Eur J Cancer. 2002;38(3):349-358.

29. Fallowfield L, Atkins L, Catt S, et al. Patients' preference for administration of endocrine treatments by injection or tablets: results from a study of women with breast cancer. Ann Oncol. 2006;17(2):205-210. 
Patient Preference and Adherence

Dovepress

\section{Publish your work in this journal}

Patient Preference and Adherence is an international, peer-reviewed, open access journal focusing on the growing importance of patient preference and adherence throughout the therapeutic continuum. Patient satisfaction, acceptability, quality of life, compliance, persistence and their role in developing new therapeutic modalities and compounds to optimize clinical outcomes for existing disease states are major areas of interest. This journal has been accepted for indexing on PubMed Central. The manuscript management system is completely online and includes a very quick and fair peer-review system. Visit http://www.dovepress.com/ testimonials.php to read real quotes from published authors.

Submit your manuscript here: http://www.dovepress.com/patient-preference-and-adherence-journal 